\title{
Mechanisms of intermolecular homologous recombination in plants as studied with single- and double-stranded DNA molecules
}

\author{
Marcel J.A.de Groot, Remko Offringa', Mirjam P.Does ${ }^{1}$, Paul J.J.Hooykaas ${ }^{1}$ and \\ Peter J.M.van den Elzen ${ }^{1}$ \\ MOGEN International nv, Einsteinweg 97, 2333 CB Leiden and 'Institute of Molecular Plant Sciences, \\ Clusius Laboratory, Leiden University, Wassenaarseweg 64, 2333 AL Leiden, The Netherlands
}

Received February 14, 1992; Revised and Accepted May 4, 1992

\begin{abstract}
To elucidate the mechanism for intermolecular homologous recombination in plants we cotransformed Nicotiana tabacum cv Petit Havana SR1 protoplasts with constructs carrying different defectlve derivatives of the NPTII gene. The resulting kanamycin resistant clones were screened for possible recombination products by PCR, which proved to be a valuable technique for this analysis. Our results show that the double-stranded circular DNA molecules used in this study recombine predominantly via a pathway consistent with the single-strand anneallng (SSA) model as proposed for extrachromosomal recombination in mammallan cells. In the remaining cases recombination occurred via a single reciprocal recombination, gene conversion and possibly double reciprocal recombination. Since single-stranded DNA is considered to be an important intermediate in homologous recombination we also established the recombination abllity of single-stranded DNA in intermolecular recombination. We found that singlestranded DNA enters in recombination processes more efflciently than the corresponding double-stranded DNA. This was also reflected in the recombination mechanisms that generated the functional NPTII gene. Recombination between a single-stranded DNA and the complementing DNA duplex occurred at similar rates via a single reciprocal recombination and the SSA pathway.
\end{abstract}

\section{INTRODUCTION}

Recently, it was demonstrated that plants can mediate extrachromosomal homologous recombination between two DNA molecules that are co-introduced into the cell via either direct gene transfer (1 -4) or Agrobacterium mediated transformation (5). These studies revealed that the efficiency of recombination depends on the topological state of the DNA and the length of homologous overlap between the DNA molecules. However, the mechanism of recombination has so far not been elucidated. In mammalian cells extrachromosomal recombination has been studied in more detail. The general strategy in these studies was to monitor the reconstitution of a functional gene encoding a selectable marker from two defective copies of the gene. It was established that introduction of a double-strand break in the region of homology of one of the recombining DNA molecules enhanced recombination considerably. Subsequent analysis of the recombination products revealed that they were the result of either gene conversion or reciprocal recombination. Based on these observations it was postulated that the double strand break repair (DSBR) model, which was originally proposed to explain recombination in yeast (6), can also account for intermolecular recombination in mammalian cells $(7-16)$. However, cleavage of both DNA molecules led to an even greater stimulation of recombination. Together with the observation that recombination between DNA molecules in mammalian cells is largely nonconservative, which means that parts of the parental molecules are lost during the process, this led to the proposal of a second model, the single-strand annealing (SSA) model (17-25). Both models are based on the observation that recombination is enhanced by double-strand breaks at specific positions in the DNA molecules. The outcomes of the recombination processes however are very different for the two models (figure 1). The DSBR model (6) requires a double strand break in the region of homology of one of the participating DNA molecules to initiate the recombination event. The double strand break is enlarged to a gap and then repaired by using the other DNA molecule that shares homology with the regions flanking the double strand break. Assuming that there is no bias in resolution of the recombination intermediate a noncrossover or crossover configuration of the flanking markers will be formed with equal frequency. Since all starting sequences are recovered in the products the reaction is conservative. In the SSA model (20) both DNA molecules must contain a double strand break. The double strand breaks will function here as the entry sites for a strand specific exonuclease which will degrade one of the DNA strands and generate complementary single stranded DNA stretches. Alternatively, unwinding by a helicase can generate the complementary single stranded DNA stretches (25). Pairing of the two partner strands and subsequent repair will reconstruct an intact gene which has an exchange of flanking markers in all cases. This reaction is nonconservative. 
In this study we performed experiments in Nicotiana tabacum cv Petit Havana SR1 to elucidate the mechanism of intermolecular homologous recombination in plants. For the detection of homologous recombination events we used different defective derivatives of the NPTII gene which give rise to a functional NPTII gene after recombination. Subsequently, integration of this restored NPTII gene into the genome confers a kanamycin resistant phenotype to the plant cell. In these experiments we cotransformed both constructs as circular molecules, because the introduction of double strand breaks in either or both of the cotransformed DNA molecules could bias the recombination mechanism to the DSBR or SSA pathway. Since both the DSBR and SSA model propose single-stranded DNA as an intermediate in homologous recombination $(6,20)$ we compared the recombination ability of double-stranded and single-stranded DNA molecules in intermolecular recombination experiments. Previous studies in our group (26) as well as in other groups $(27,28)$ demonstrated already that single-stranded DNA can transform plant protoplasts efficiently. To distinguish between the two proposed models we set up a PCR system to screen selected recombinant $\mathrm{Km}^{r}$ calli for the different possible outcomes of recombination.

\section{MATERIALS AND METHODS}

\section{Plasmid constructions}

Standard cloning steps were performed following Sambrook et al. (29). Restriction and modifying enzymes were purchased from Bethesda Research Laboratories and Biolabs and were used under the conditions recommended by the supplier. For bacterial cloning in which pUC vectors were involved Escherichia coli $\mathrm{K} 12$ strain

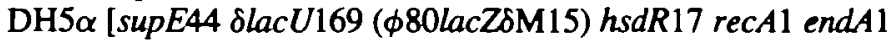
gyrA96 thi-1 relA1] was used. For the M13 derived plasmids strain JM101 [supE thi $\delta$ (lac-proAB) $\mathrm{F}^{\prime}\left[\right.$ traD36 proAB ${ }^{+}$lac/ lacZSM15]] was used.

The NPTII gene used in these constructions was derived from the binary vector pSDM 100 (5). The positive control construct pSDM2 (figure 2) was obtained by cloning the nos promoter, the NPTII gene and the ocs terminator in pUC12. Plasmid pSDM4 was made from pSDM 2 by inserting an unique $X$ hoI site in the EcoRI polylinker site flanking the nos promoter. The 5' deletion construct (pSDM1001) was made by replacing the $B c I / X$ maII fragment, encompassing most of the nos promoter and part of the NPTI gene encoding the first twelve aminoacids, by an EcoRI linker. In order to obtain the 3 ' deletion construct (pSDM1004) the supF gene, the ocs terminator and part of the NPTII gene up to the RsrII site in the NPTII coding region were eliminated. To be able to isolate single-stranded DNA, the HindIII-XhoI fragment from pSDM 1004 carrying the $3^{\prime}$ deleted NPTII gene was cloned into M13 mp18 and mp19 vectors, resulting in pSDM8004 and pSDM9004. The vectors differ in the orientation of the NPTII insert with regard to the surrounding M13 sequences (figure 2). Double-stranded DNA samples were named pSDM8004RF and pSDM9004RF and single-stranded DNA samples pSDM8004ss and pSDM9004ss, respectively. The positive control constructs pSDM4M-RF and PSDM4Mss (figure 2) were obtained by cloning the HindIII-XhoI fragment of PSDM4 into M13 mp18.

Large scale isolation and $\mathrm{CsCl}$ purification of plasmid DNA, M13 RF and ss DNA was performed as described (29). DNA concentration was determined by measuring the optical density at 260 and $280 \mathrm{~nm}$.

\section{Plant cell transformation}

Mesophyll protoplasts were prepared from leaves of 5-8 week old axenically grown Nicotiana tabacum cv. Petit Havana SR 1 plants by overnight incubation of leaves at $26^{\circ} \mathrm{C}$ in $\mathrm{K} 3$ medium (30) containing $0.4 \mathrm{M}$ sucrose, $1 \%$ cellulase $\mathrm{R} 10,0.1 \%$ macerozyme R10 and $0.1 \%$ MES. The protoplasts were sieved, washed twice in $\mathrm{K} 3 \mathrm{~A}(31)$ and resuspended in electroporation buffer (0.4 M mannitol, $6 \mathrm{mM} \mathrm{MgCl} 2,0.5 \% \mathrm{MES} \mathrm{pH} 5.6)$ at a density of $1.5 \times 10^{6}$ per $\mathrm{ml}$ (32). An aliquot of $0.33 \mathrm{ml}$ protoplasts was incubated for 5 minutes at $45^{\circ} \mathrm{C}$ and cooled to

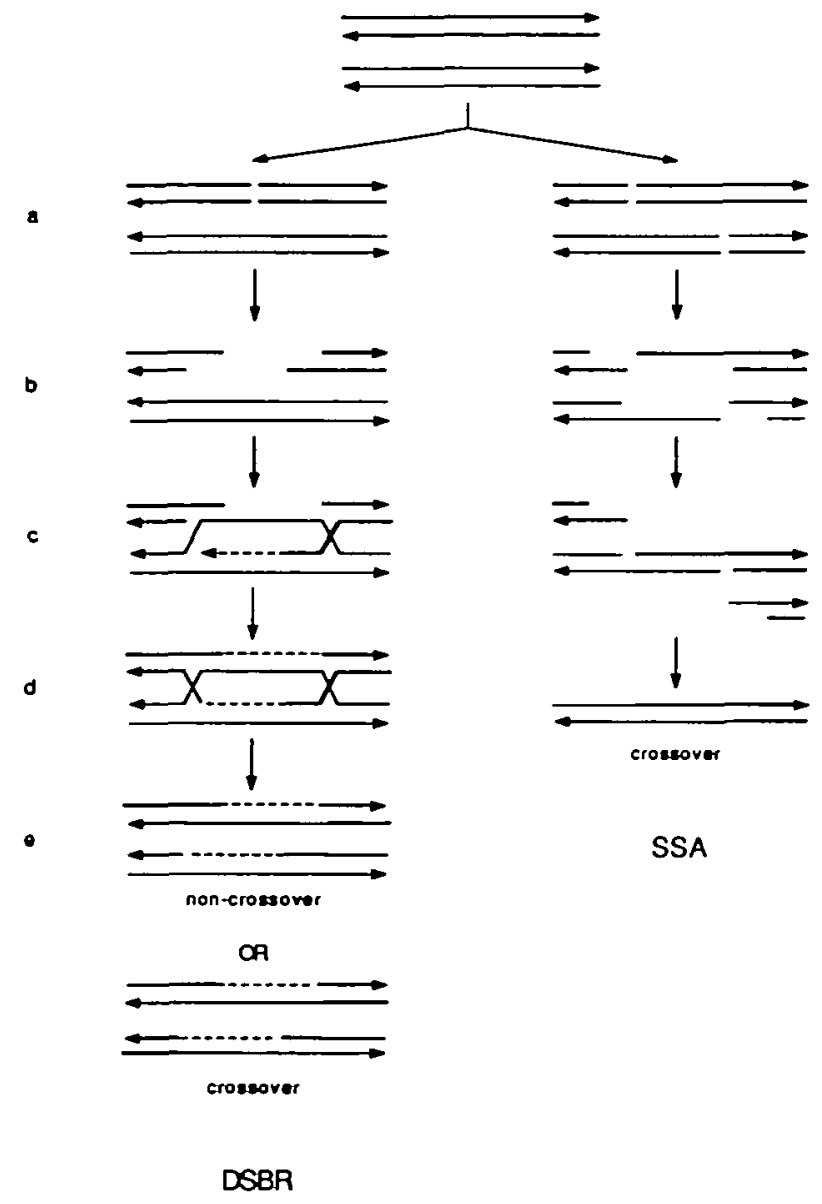

Figure 1. The Double Strand Break Repair (DSBR) model and the Single Strand Annealing (SSA) model as proposed to describe extrachromosomal homologous recombination in mammalian cells. The arrows point to the 3' ends of the DNA molecules. The DSBR model: a. A double strand break is made in one DNA molecule. b. Creation of a gap leaving a 3 ' overhanging single strands. $c$. One single strand invades the homologous DNA duplex and generates a D loop. The $D$ loop is enlarged by repair synthesis until it can anneal to the other overtanging $3^{\prime}$ end. d. Gap repair is completed by repair synthesis from the other $3^{\prime}$ end, branch migration will lead to the formation of two Holliday junctions. e. The crossover intermediate can be resolved in two different non-crossover and crossover configurations. In this figure, cutting the inner strands of both Holliday junctions created the non-crossover configuration. The crossover configuration was created by cutting the right Holliday junction at the inner strand. The SSA model: a. A double strand break is made in both DNA molecules. b. Creation of complementary single strands by an exonuclease or a helicase. $c$. Annealing of the two DNA molecules and repair synthesis will generate a recombinant motecule with its flanking markers exchanged. During the process parts of the original molecules are lost. The figure for the DSBR model was adapted from Szostak et al. (6) and for the SSA model from Lin et al. (21). 
room temperature on ice. Hereafter $10 \mu \mathrm{l}$ of DNA solution (1 $\mu \mathrm{g} / \mu \mathrm{l})$ was added followed by $0.17 \mathrm{ml}$ of PEG solution (24\% w/v PEG6000, $30 \mathrm{mM} \mathrm{MgCl} 2$ in $0.4 \mathrm{M}$ mannitol, pH 5.6). In case of cotransformations with pSDM1001 and pSDM1004 10 $\mu \mathrm{l}(1 \mu \mathrm{g} / \mu \mathrm{l})$ of each plasmid was added. In cotransformations with RF and ss DNA of PSDM8004 and pSDM9004, DNA was added in equimolar quantities (respectively $22 \mu \mathrm{l}$ and $11 \mu \mathrm{l}$ of $1 \mu \mathrm{g} / \mu \mathrm{l} \mathrm{RF}$ and ss DNA) to PSDM 1004. Ten minutes after the addition of DNA and PEG the sample was electroporated using the Promega Biotec X-Cell 450 Electroporation System. The pulse setting was $14.3 \mathrm{~ms}, 350 \mathrm{~V}$ and $1550 \mu \mathrm{F}$. Another 10 minutes later the protoplasts were embedded in agarose beads by adding $9.5 \mathrm{ml}$ of a $1: 1$ mixture of $\mathrm{K} 3 \mathrm{~A}$ and $\mathrm{H}$ media containing $0.4 \% \mathrm{w} / \mathrm{v}$ Low Melting Type agarose (Sigma). The protoplasts were cultured in the bead type culture system (31). Selection for kanamycin resistance was performed by adding $50-100 \mathrm{mg} / \mathrm{l}$ kanamycin. In the period from three till eight weeks after electroporation calli were transferred to solid MS30 medium (33) containing $1 \mathrm{mg} / 1 \alpha$-naphthalene acetic acid (NAA), $0.2 \mathrm{mg} / 1$ benzylaminopurine (BAP) and $100 \mathrm{mg} / \mathrm{l}$ kanamycin. To determine the plating efficiency one fourth part of a bead was incubated in medium without selection.

\section{Isolation of DNA from callus tissue and PCR-analysis}

Plant DNA was isolated from callus (100 mg) according to Lassner et al. (34). The polymerase chain reactions were performed in a Perkin Elmer Cetus DNA Thermal Cycler $\mathbf{4 8 0}$ using $1 \mu \mathrm{g}$ genomic DNA, $25 \mathrm{pMol}$ of each primer, $10 \mathrm{nMol}$ of each dNTP (Sigma), 3 units of Taq DNA polymerase (Promega) and $10 \mu \mathrm{l}$ of $10 \times \mathrm{Taq}$ DNA polymerase buffer (Promega) in a total volume of $100 \mu \mathrm{l}$. The reactions were overlaid with $55 \mu \mathrm{l}$ mineral oil. The amplification was started with one cycle of $2 \mathrm{~min}$ at $95^{\circ} \mathrm{C}, 1 \mathrm{~min}$ at $57^{\circ} \mathrm{C}$ and $2 \mathrm{~min}$ at $72^{\circ} \mathrm{C}$, followed by 35 cycles of $1 \mathrm{~min}$ at $95^{\circ} \mathrm{C}, 1 \mathrm{~min}$ at $57^{\circ} \mathrm{C}$ and $2 \mathrm{~min}$ at $72^{\circ} \mathrm{C}$. The final cycle was $1 \mathrm{~min}$ at $95^{\circ} \mathrm{C}, 1 \mathrm{~min}$ at $57^{\circ} \mathrm{C}$ and $10 \mathrm{~min}$ at $72^{\circ} \mathrm{C}$. One quarter of the sample was analyzed on a $1 \%$ agarose gel. The sequences of the primers that were used are: 1: 5'-GAACTGACAGAACCGCAACG-3'; 2: 5'-ACCGTAAAGCACGAGGAAGC-3'; L1: 5'-CGACGTTGTAAAACGACGGC-3'; LR2: 5'-CACAGGAAACAGCTATGACC-3'; P1: 5'-AACTGAAGGCGGGAAACGAC-3'.

\section{Southern analysis}

PCR products were separated on a $1 \%$ agarose TBE gel. DNA was transferred to a Hybond- $\mathrm{N}^{+}$membrane (Amersham) by capillary alkali blotting. Prehybridization, hybridization and washing steps were according to the Hybond protocol. DNA probes labelled with $\alpha^{-32} \mathrm{P}-\mathrm{dCTP}$ (specific activity: $0.5-1.0 \times 10^{9} \mathrm{dpm} / \mu \mathrm{g} \mathrm{DNA}$ ) were obtained using the random primers labelling kit of BRL.

\section{RESULTS}

\section{Experimental design}

In order to examine the mechanism of intermolecular recombination in plants, protoplasts of Nicotiana tabacum cv Petit Havanna SR1 were electroporated with pairs of circular plasmids of which one contained a $5^{\prime}$ deletion (pSDM 1001) and the other a 3' deletion (pSDM1004, pSDM8004 and pSDM9004) in the NPTII gene (figure 2). When both constructs are co-introduced in a protoplast, an intact NPTI gene can be formed via homologous recombination in the 613 bp overlapping homologous region. Upon integration into the genome this will confer a kanamycin resistant phenotype to the plant cell.

To compare the recombination ability of single-stranded DNA and double-stranded DNA molecules, the 3 ' deletion mutant NPTII gene was cloned into M13 vectors which allowed the isolation of both double-stranded RF (replicative form) DNA and single-stranded DNA of the same construct. As shown in figure 2 the constructs pSDM1001 and pSDM1004, pSDM8004 or pSDM9004 have different degrees of vector homology. This enabled us to establish the effect of vector homology on the recombination frequency.

To analyze the mechanism of extrachromosomal recombination in plants we used selected $\mathrm{Km}^{\mathrm{r}}$ calli obtained after cotransformation of pSDM1001 and pSDM9004. The difference in sequences flanking the NPTI gene in these constructs offered the possibility to use PCR for the detection of the different recombination products. With this combination of constructs there are four different ways by which an intact NPTI gene might be formed (figure 3). These four ways can be explained by either of the two models proposed for intermolecular homologous recombination. 1. A single reciprocal recombination in the homologous region between the $5^{\prime}$ and 3 ' deletions would create both an intact NPTII gene and a reciprocal recombination product carrying the $5^{\prime}$ and $3^{\prime}$ deletions. This type of recombination would lead to an exchange of the flanking sequences in the intact NPTII gene. 2. A recombination on both sides (double reciprocal recombination) of the $5^{\prime}$ deletion on PSDM1001 with the corresponding region of pSDM9004 would generate an intact NPTII gene without an exchange of flanking sequences. Also in this case a reciprocal recombination product containing both deletions would be formed. 3. Gene conversion, being the nonreciprocal transfer of information from one DNA duplex to

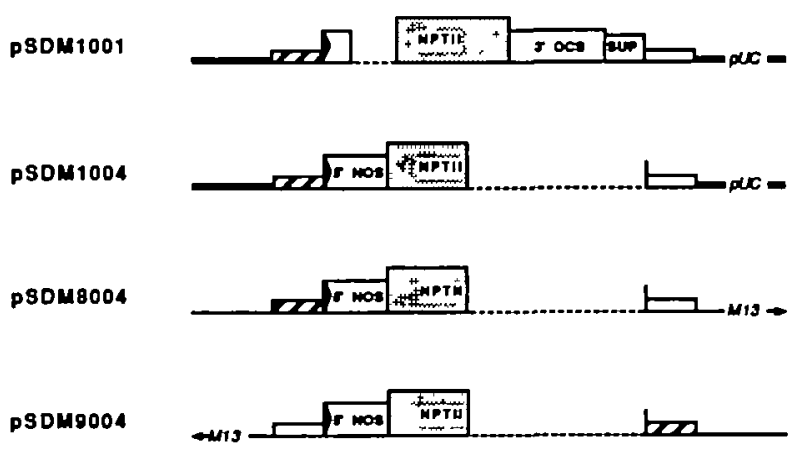

Positive controls

PSDM2

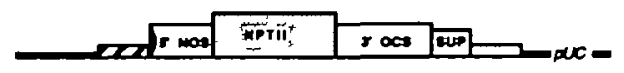

PSDLAM

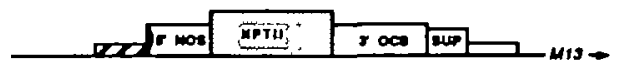

Figure 2. Constructs used in the cotransformation experiments. Abbreviations: 5 ' NOS = promoter region of the nopaline synthase gene; NPTI = region coding for neomycin phosphotransferase II; $3^{\prime}$ OCS = transcription terminator of the octopine synthase gene; SUP = E. coli supF gene. The lacZl $\alpha$ ) sequences fanking the NPTII insert are indicated by the striped and dotted boxes. pUC and M13 vector sequences are indicated. 
another, could restore the $5^{\prime}$ deletion of pSDM1001 using the $5^{\prime}$ region of pSDM9004 as a donor template. This would as well generate an intact NPTI gene without an exchange of the flanking sequences. However, in this case a pSDM9004 construct which is not changed by the recombination would be present. Due to the absence of homology on the $3^{\prime}$ side of the $3^{\prime}$ deletion, it is not likely that restoration of pSDM9004 occurs via double reciprocal recombination or gene conversion. These three recombination mechanisms can all be explained by the DSBR model. 4. Based on the SSA model for recombination a fourth type of recombination product can be imagined. This model would involve the generation of complementary single stranded DNA in the region between the $5^{\prime}$ and $3^{\prime}$ deletions of pSDM 1001 and pSDM9004 respectively, followed by pairing and repair. During the recombination process parts of the parental constructs are lost and therefore, only the selected intact NPTI gene would be obtained. This recombination product would contain an exchange of flanking sequences in every case.

It is important to note that due to the selection on kanamycin, only lines in which recombination led to a functional gene were analyzed. Therefore, it could be argued that the reciprocal recombination product is lacking because we do not select for its integration into the plant genome. However, a single reciprocal recombination event between the circular constructs pSDM1001 and pSDM9004 should result in a contiguous product of recombination. Thus, if we detect one of the products of recombination, the selected product, we should also detect the reciprocal product with nearly equal frequency. After a double reciprocal recombination the intact NPTI gene and the reciprocal recombination product carrying both deletions will be on separate molecules and therefore in this case co-integration would be a matter of chance although it might be frequent. Schocher et al. (35) demonstrated that non-selectable DNA cointegrated with selectable DNA in up to $88 \%$ of the selected clones. Detection of a pSDM9004 construct which was involved in gene conversion would also be a matter of chance and besides, might be obscured by cointegrated pSDM 9004 molecules not participating in the reaction.

To detect the recombination products with PCR we have chosen the following primer combinations (figure 3 ). The primers $1+$

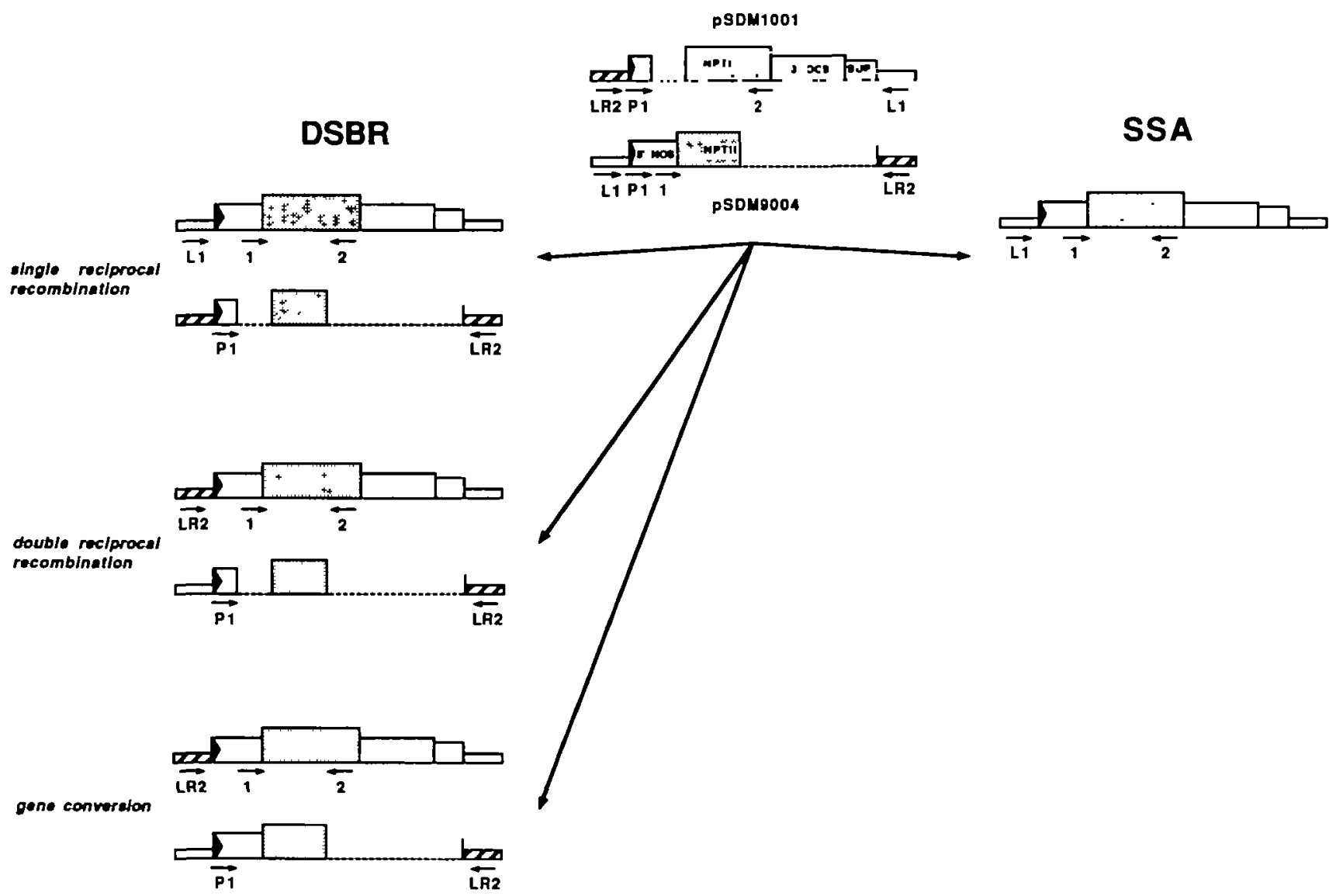

Figure 3. The constructs PSDM1001 and PSDM9004 are depicted in the top of the figure, only the NPTIl insert and the flanking lacZ( $\alpha$ ) sequences (dotted and striped boxes) are shown. Betow the construct pSDM 1001 and pSDM9004 all the primers are indicated which are used to discriminate between the possible recombination proctucts. The recombination products generated by 1 . single reciprocal recombination; 2 . double reciprocal recombination; 3 . gene conversion and 4 . SSA are shown. For the recombination products only the primers used to amplify that product are indicated. The primer combination $1+2$ will lead to the amplification of a 980 bp fragment specific for a restored NPTH gene, the primer combination $2+$ L1 will lead to amplification of a 1298 bp fragment specific for an intact NPTII gene in which an exchange of flanking sequences has occurred (single reciprocal recombination and SSA). The primer combination $2+$ LR2 will amplify both a 1287 bp fragment specific for an intact NPTI gene in which no exchange of flanking sequences occurred (double reciprocal recombination and gene conversion) and a $938 \mathrm{bp}$ fragment specific for an extra integrated pSDM 1001 construct. The primer combination P1 + LR2 will amplify a reciprocal recombination product of 699 bp containing both deletions (single- and double reciprocal recombination) and a 1048 bp fragment specific for an extra integrated pSDM9004 construct. 
2 , annealing in the regions of the two deletions, will amplify a fragment only after an intact NPTII gene has been formed via recombination. This will confirm that the kanamycin resistant phenotype of the selected lines is indeed due to recombination. Whether there has been an exchange of the flanking sequences or not can be detected after amplification with the primers $2+$ $\mathrm{L} 1$ or $2+\mathrm{LR} 2$, respectively. The primer combination $2+\mathrm{LR} 2$ will detect also integrated pSDM1001 copies. Reciprocal recombination products containing both deletions as well as integrated pSDM9004 copies will be detected by amplification with the primers P1 + LR2.

Summarizing, an exchange of flanking sequences as detected by amplification with the primers $2+\mathrm{Ll}$ is indicative for recombination via either a single reciprocal recombination or single strand annealing (SSA). The presence of a reciprocal recombination product as detected by amplification with the primers P1 + LR2 will discriminate between these mechanisms. No exchange of the flanking sequences as detected by amplification with the primers $2+L R 2$ is indicative of a double reciprocal recombination or gene conversion. The presence of a reciprocal recombination product as detected by amplification with the primers P1 + LR2 would be a strong indication for a double reciprocal recombination event. Thus we are able to distinguish the four ways by which an intact NPTII gene can be formed in our experiments, since they each yield a characteristic recombination product.

Recombination frequencies of double-stranded and singlestranded DNA molecules

As shown in table 1 cotransformation of the different combinations of defective NPTII genes gave $\mathrm{Km}^{\mathrm{r}}$ calli in all

Table 1. Restoration of kanamycin resistance in protoplasts of Nicotiana tabacum Petit Havana SR1 after simultaneous introduction of double- and single-stranded defoctive NPTII genes via electroporation.

\begin{tabular}{ll}
\hline NPTII construct & $\mathrm{Km}^{r}$ calli/electroporation(*) \\
\hline Cotransformations & \\
pSDM1001 + pSDM1004 (pUC) & $9 \pm 3$ \\
pSDM8004RF & $17 \pm 5$ \\
PSDM8004ss & $25 \pm 6$ \\
pSDM9004RF & $15 \pm 5$ \\
pSDM9004ss & $28 \pm 10$ \\
Positive controls & \\
PSDM2 & \\
pSDM4MRF & $422 \pm 2$ \\
pSDM4Mss & $807 \pm 105$ \\
\hline
\end{tabular}

Data are based on two independent experiments in which 5 electroporations $\left(2.5 \times 10^{6}\right.$ protoplasts) were performed for each combination of constructs and 2 electroporations for the positive control constructs. As a negative control 16 electroporations ( $8 \times 10^{6}$ protoplasts) were performed with either $p S D M 1001$ or pSDM1004 and 6 electroporations $\left(3 \times 10^{6}\right)$ with either pSDM8004 or pSDM9004.

The $t$-test was employed to determine whether the mean numbers of $\mathrm{Km}^{\mathrm{r}}$ calli/ electroporation as obtained for the different combinations of constructs are significantly different from each ocher. All the combinations were tested in pairs, the confidence limit was 5\%. The combinations of pSDM1001+ pSDM1004 and pSDM1001+pSDM8004RF or pSDM1001+pSDM8004ss or pSDM1001+ pSDM9004RF or pSDM $1001+$ pSDM9004ss were significantly different. The same was true for the combination pSDM $1001+$ pSDM8004RF and pSDMI001+ pSDM8004ss. However, the combination pSDM1001+pSDM9004RF and pSDM1001 + pSDM9004ss was not significantly different while it was significantly different when the results of the two experiments were considered separately. $(*) \pm$ standard deviation cases. When the recombination frequencies between the double stranded DNA constructs pSDM1001 and pSDM1004, pSDM8004RF or pSDM9004RF were compared, a few remarkable differences appeared. Although pSDM1004 shares complete vector homology with pSDM1001, this combination showed the lowest recombination frequency. Constructs pSDM8004RF and pSDM9004RF share next to the NPTII insert only limited or no contiguous vector homology with pSDM1001, but gave in combination with pSDM1001 a 1.8 and 1.6-fold higher recombination frequency than pSDM1004. However, in parallel electroporations with the positive control constructs pSDM4M-RF (M13) or pSDM2 (pUC) a similar difference in transformation frequency was observed. These results suggest that the observed difference in recombination frequency between pSDM1004 and pSDM8004 or pSDM9004 is due to a more efficient transformation of the M13RF DNA than the pUC DNA. Apparently, vector homology has no significant effect on the efficiency of recombination. When the recombination frequencies

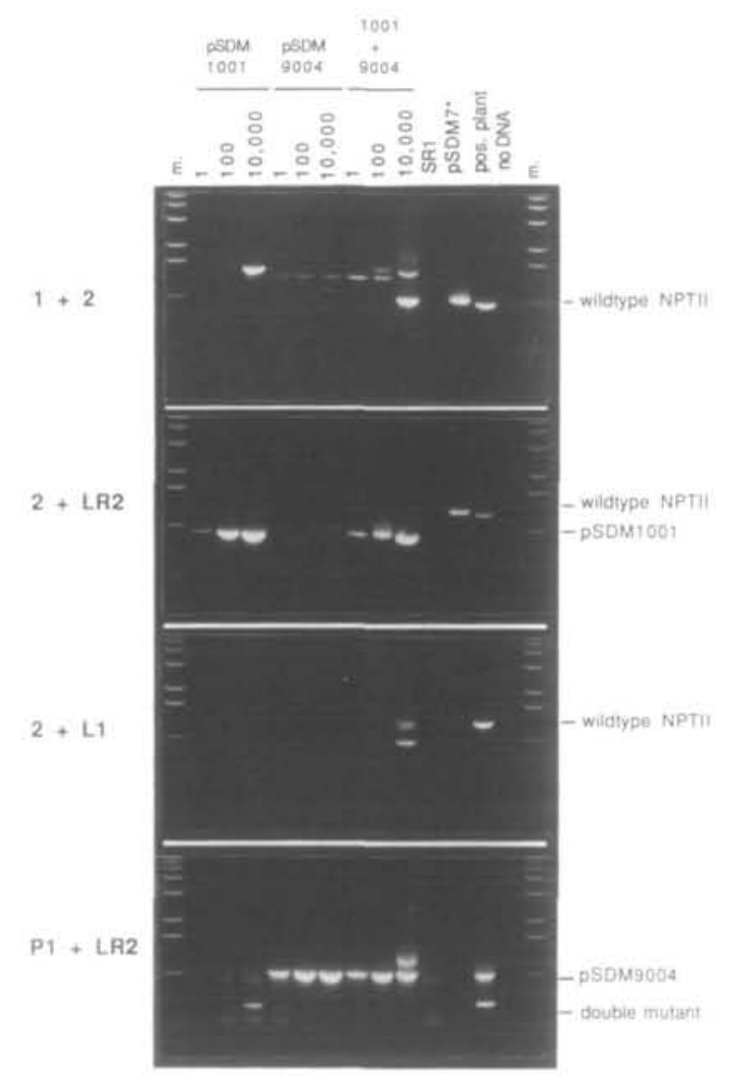

Figure 4. PCR control experiment. PCR was performed on 1 / g genomic tobacco DNA mixed with different amounts of pSDM1001, pSDM9004RF DNA or the combination of these two. The amounts of plasmid DNA and the constructs are indicated on top of the figure $(1,100$ and $10,000=1,100$ and $10,000 \mathrm{pg})$. SR 1 $=1 \mu \mathrm{g}$ of tobacco DNA; pSDM7* = Ipg of a construct containing the intsct NPTII gene (should give a PCR fragment for primers $1+2$ or $2+$ LR2 only); Pos. plant $=1 \mu \mathrm{g}$ DNA of a tobacoo plant transformed with an intact NPTII gene (only primers $1+2$ and $2+L R 2$ ), 1 pg plasmid control (primers $2+$ LI) and 1 $\mu \mathrm{g}$ DNA of recombinant plant containing pSDM9004 and double reciprocal product $(\mathrm{P1}+\mathrm{LR} 2) ;$ no DNA $=$ a PCR reaction without DNA; $m$ * I kb size marker. On the left side, the primer combinations used in the PCR analysis are indicated. On the right side, the recombination products and the parental constructs are indicated. 
of the double-stranded (RF) DNA and single-stranded DNA versions of pSDM8004 and pSDM9004 were compared, it was found that the use of single-stranded DNA resulted in a small but significant 1.5 and 1.9-fold enhancement of recombination. In this case the single- and double-stranded DNA samples of the positive control construct pSDM4M showed nearly equal transformation frequencies. Therefore we conclude that the use of single-stranded DNA as transforming agent offers an advantage to the recombination machinery.

In control experiments where we transformed all the constructs individually we never obtained kanamycin resistant calli (table 1). This excluded both a spontaneous restoration of the mutant genes as well as a contamination of the different DNA preparations with an intact NPTU gene.

We took selected $\mathrm{Km}^{\mathrm{r}}$ lines obtained after cotransformation with the combination pSDM1001 and pSDM9004 as representative for the analysis of the mechanism of intermolecular homologous recombination, since there was no difference in recombination frequency between the pSDM8004 and pSDM9004 constructs.

The PCR technique is suitable for the analysis of recombination products

PCR analysis has proven to be very useful for the selective detection of homologous recombination in animal cells $(36-38)$. Nevertheless, it was very important to verify the reliability of PCR for the detection of recombination products since it has been shown that chimeric molecules can sometimes be created by PCR directed homologous recombination $(39-41)$. Therefore, we performed the following control experiment. For all the primer combinations, PCR was performed on $1 \mu \mathrm{g}$ of untransformed tobacco DNA mixed with different amounts $(1,100$ and 10,000 pg) of pSDM1001, pSDM9004RF DNA or the combination of these two. As shown in figure 4 none of the reactions with the primer combination $2+$ LR2 led to amplification of a recombination product. When each plasmid was used individually in PCR with the primer combinations $1+2$ and $2+\mathrm{Ll}$ no recombination products were found. However, in the reaction containing $10,000 \mathrm{pg}$ of both plasmids a recombination product was amplified. The primer combination P1 + LR2 with 10,000 $\mathrm{pg}$ of pSDM1001 as a substrate, led to the amplification of a fragment slightly smaller than the expected double mutant recombination product. However, this fragment was not obtained when both plasmids were amplified simultaneously.

Our results show for all primer combinations that PCR with $100 \mathrm{pg}$ of pSDM 1001 and pSDM9004RF as a substrate did not lead to amplification of recombination products. This amount is equivalent to the presence of approximately 300 copies of each plasmid in the tobacco genome. In previous studies with Southem analysis on more than 50 transgenic plants obtained after electroporation (not shown) we detected at most a few dozen of integrated copies. Other reports on direct gene transfer $(42,43)$ in plants reported the integration of similar copy numbers. From these experiments we conclude that in the analysis of selected $\mathrm{Km}^{\mathrm{r}}$ calli the formation of a PCR directed recombination product is highly unlikely and that PCR analysis with the primers mentioned above is a reliable and efficient method for the analysis of recombination.

Analysis of recombination products formed after cotransformation of double-stranded DNA molecules

After cotransformation of pSDM1001 and pSDM9004 we picked randomly 93 individual $\mathrm{Km}^{\mathrm{r}}$ calli from ten independent electroporations. DNA was isolated from these calli and each sample was subjected to PCR with the four primer combinations mentioned earlier (figure 3). The result of the PCR analysis on these calli is shown in figure 5A. The fact that the kanamycin resistant phenotype of all the analyzed calli was indeed due to recombination was confirmed by PCR with the primers $1+2$ which led to amplification of the expected fragment in all cases. What is clear from figure 5A is that 62 out of the 93 recombinant calli analyzed contain an intact NPTI gene of which the flanking sequences had been exchanged. In the majority (50 out of 62) of these lines no reciprocal recombination product containing both
A

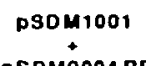

pSDM9004 RF

double-stranded
B

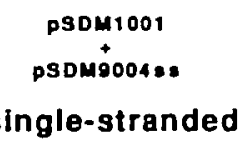

recombination

(1. 2)

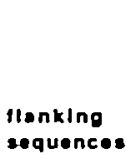

sequences

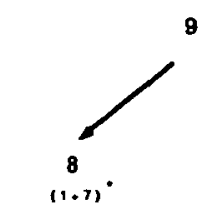

no exchange

(2) LnT)

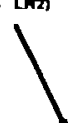

reciprocal

recombinatlon

product

(P1 + LA2)
3

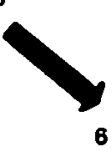

62

axchenge

(2. (1)

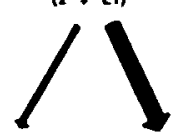

12

present single-stranded

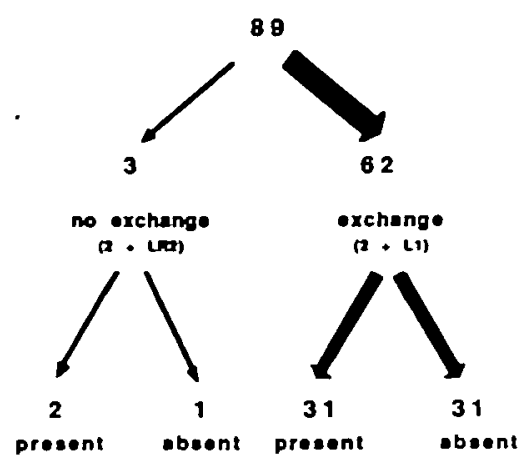

Figure 5. Overview of the PCR analysis on kanamycin resistant calli obtained after cotransformation of pSDM1001 and pSDM9004 (RF and ss). * 7 out of these 8 calli contained also an intact NPTII gene in which the flanking sequences were exchanged. The other way around, 7 out of these 62 calli contained also an intact NPTII gene where no exchange of flanking sequences occurred. 
deletions was detected. This exchange of flanking sequences and the lack of a reciprocal recombination product indicates that recombination proceeded primarily in accordance with the predictions of the SSA model (figure 3). A reciprocal recombination product containing both deletions was detected in only 12 out of 62 lines containing the intact NPTII gene of which the flanking sequences had been exchanged. This combination of recombination products is expected after recombination via a single reciprocal recombination and shows that, although with lower frequency, also a conservative recombination pathway operates in plant cells. In addition to this other mechanisms of recombination occurred. Eight of the 93 lines analyzed turned out to contain an intact NPTI gene of which the flanking sequences had not been exchanged. In these lines no reciprocal recombination product containing both deletions was detected but all contained at least one copy of the pSDM9004 construct. Therefore, in these calli the formation of an intact NPTII gene was most likely the result of gene conversion but a double reciprocal recombination cannot be excluded. It is remarkable that 7 out of these 8 calli also contained a second copy of the NPTII gene for which the flanking sequences had been exchanged. Apparently, two independent recombination events occurred after transformation of these lines. An example of the recombination products that were detected by PCR analysis in a number of different $\mathrm{Km}^{r}$ calli is shown in figure 6 . Southern blotting of the gel with a NPTII specific probe, which shared no homology with the primers, was used to demonstrate that all the amplified recombination products indeed contained NPTII sequences.

The results in figure 5A show that while all the 93 individual calli analyzed with the primers $1+2$ contained the fragment diagnostic for a recombination, we could detect in only 63 calli if an exchange of flanking sequences had occurred. In the

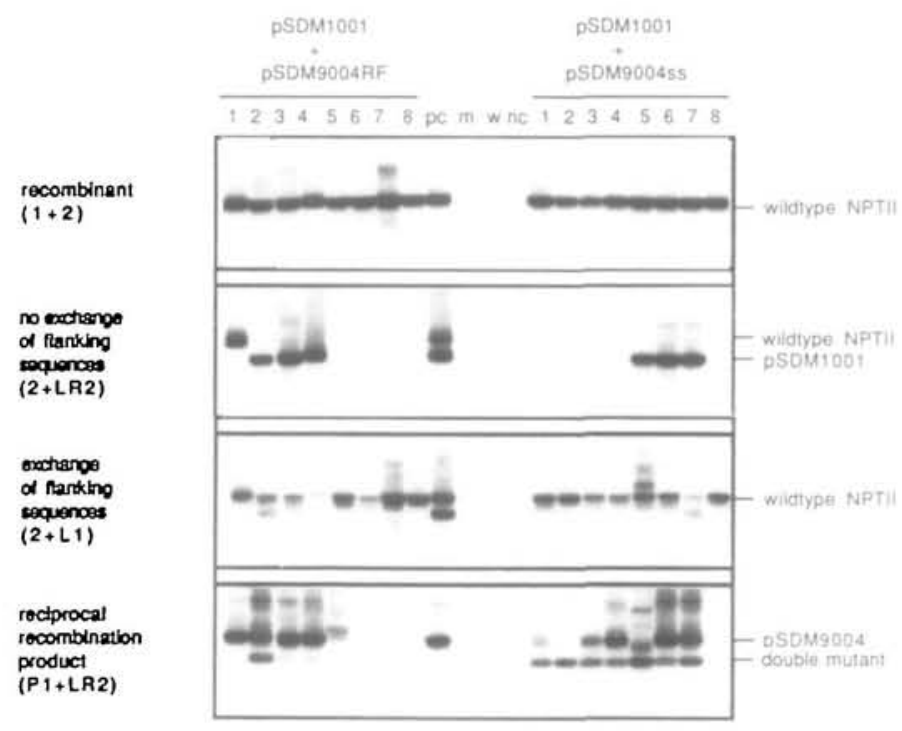

Figure 6. Southem blo of amplified recombination products obtained in PCR analysis on $\mathrm{Km}^{r}$ calli selected after cotransformation of pSDM1001 and pSDM9004 (RF and ss). pc = positive control; $m=1 \mathrm{~kb}$ size marker; $w=$ a PCR reaction without DNA; $n c=1 \mu g$ of tobacco DNA. The bto was hybridized with a NPTII probe complementary to the NPTII sequences located between the $S^{\prime}$ and $3^{\prime}$ deletion. This probe does not contain any homology to the primers used in the PCR analysis. remaining lines the annealing sites for primer L1 or LR2 were probably lost. Since these sites are located in the $\operatorname{lacZ}(\alpha)$ sequences which are not essential to the NPTII gene they can be lost without influencing the kanamycin resistant phenotype. Primers L1 and LR2 anneal at similar positions very close to the NPTII gene which meant that the primer combinations $2+$ $\mathrm{L1}$ and $2+\mathrm{LR} 2$ both led to amplification of a $1300 \mathrm{bp}$ fragment. Therefore, we conclude that the detection of these amplification products is equally prone to loss of the annealing site and reflects the actual rate of exchange of flanking sequences.

The PCR analysis we performed offered the opportunity to detect the presence of extra integrated copies of the parental constructs pSDM1001 and pSDM9004. Cotransformation and co-integration of extra parental constructs did occur very frequently as shown in table 2 . An extra pSDM1001 construct was integrated in $33 \%$ of the analyzed $\mathrm{Km}^{\mathrm{r}}$ calli, while pSDM9004 was present even more frequently in $59 \%$ of the $\mathrm{Km}^{\mathrm{r}}$ calli. Multiplication of these percentages gives $19 \%$, which is similar to $22 \%$ of the $\mathrm{Km}^{\mathrm{r}}$ calli containing both parental constructs as detected by PCR. This indicates that transformation of both parental constructs is independent of each other.

Analysis of recombination products formed after cotransformation of double-stranded and single-stranded DNA molecules

Genomic DNA from 89 randomly picked $\mathrm{Km}^{r}$ calli, obtained after cotransformation of pSDM1001 and pSDM9004ss, was subjected to PCR analysis. The result is shown in figure 5B. Just as for recombination between two double-stranded DNA constructs the majority (62 out of 89 ) of the calli analyzed contained an intact NPTII gene for which the flanking sequences had been exchanged. However, there turned out to be a remarkable shift in the degree with which the reciprocal recombination product containing the two deletions was detected. This reciprocal recombination product was in fact detected in 31 of the $62 \mathrm{Km}^{\mathrm{r}}$ calli containing an intact NPTII gene for which the flanking sequences had been exchanged. This indicates that recombination between double-stranded and single-stranded DNA molecules occurs 2.6 times more frequently via a single reciprocal recombination than recombination between doublestranded DNA molecules. In the other $31 \mathrm{Km}^{\mathrm{r}}$ calli which did not contain the reciprocal recombination product recombination occurred according to the SSA model. We observed two $\mathrm{Km}^{r}$ lines in which restoration of an intact NPTI gene occurred most likely via a double reciprocal recombination. In one line gene conversion may have occurred since it contained an intact NPTII gene for which the flanking sequences were exchanged in the presence of a copy of the pSDM9004 construct. Figure 6 shows an example of the recombination products that were detected in

Table 2. Detection of extra integrated parental constructs by PCR analysis in $\mathrm{Km}^{\prime} \mathrm{calli}$ obtained in the cotransformation of PSDM1001 and pSDM9004 (RF and ss).

\begin{tabular}{|c|c|c|}
\hline $\begin{array}{l}\text { Detocted PCR } \\
\text { fragments }\end{array}$ & $\underset{\%}{\text { pSDM1001 + pSDM9004RF }}$ & $\underset{\%}{\text { pSDMIO0I + pSDM9004ss }}$ \\
\hline $\begin{array}{l}\text { pSDM1001 } \\
\text { (PCR2+LR2) }\end{array}$ & $33 \%$ & $54 \%$ \\
\hline $\begin{array}{l}\text { pSDM9004 } \\
\text { (PCRP1 + LR2) }\end{array}$ & $59 \%$ & $76 \%$ \\
\hline pSDM1001 + pSDM9004 & $22 \%$ & $48 \%$ \\
\hline
\end{tabular}


the PCR analysis. Just as discussed for the analysis of recombination products after cotransformation of two doublestranded DNA molecules, we could detect in this case if an exchange of flanking sequences occurred in only 65 out of 89 recombinant calli.

As shown in table 2 integration of extra parental constructs was again frequent. Plasmids pSDM1001 and pSDM9004 were present in $54 \%$ and $76 \%$ of the $\mathrm{Km}^{\mathrm{r}}$ calli analyzed, respectively, while both constructs were present simultaneously in $48 \%$ of the calli. This is approximately similar to the $41 \%$ obtained after multiplication of the percentages found for the separate constructs, which indicates that the transfer of the two constructs occurred independently in these latter experiments.

\section{DISCUSSION}

The objectives of the experiments described in this report were to elucidate the mechanism of intermolecular recombination in plants and to establish the recombination ability of single stranded DNA. For this we used different derivatives of the NPTII gene carrying non-overlapping deletions. After simultaneous introduction into tobacco protoplasts of two complementing constructs either in double-stranded or single-stranded DNA form, intact NPTII genes were formed via homologous recombination. Selected $\mathrm{Km}^{\mathrm{r}}$ lines obtained after cotransformation of the constructs pSDM1001 and pSDM9004 were subjected to PCR to analyze the recombination products.

The results of the PCR analysis demonstrated that the majority of the products detected in the recombinant $\mathrm{Km}^{\mathrm{r}}$ calli, obtained after cotransformation of two double-stranded constructs, could best be explained by the SSA model for intermolecular recombination. The observation that vector homology had no significant influence on the recombination efficiency was also in line with the SSA model. Nevertheless, we also demonstrated that homologous recombination mediated via a single reciprocal recombination, gene conversion and possibly double reciprocal recombination could lead to a restored NPTII gene. Obviously, the alternative DSBR pathway does operate in plant cells, although with lower efficiency. The results obtained after transformation with the combination of a double- and singlestranded constructs showed that single-stranded DNA recombined somewhat differently from double-stranded DNA. The use of single-stranded DNA instead of double-stranded DNA resulted in a 1.5 to 1.9 higher frequency with which $\mathrm{Km}^{\mathrm{r}}$ calli were obtained. The higher recombination frequency was reflected in the recombination mechanisms which led to the generation of a restored NPTII gene. Recombination between a double-stranded and single-stranded DNA molecule occurred 2.6 times more efficiently via a single reciprocal recombination than recombination between two double-stranded DNA molecules. Apparently, the presence of single-stranded DNA allows a more extensive use of the DSBR (single reciprocal recombination) pathway for recombination, resulting in a higher frequency with which the NPTII gene is restored. The remaining recombination events that were analyzed were consistent with the predictions of the SSA model. We conclude that the form in which the DNA substrate is introduced has significant influence on the recombination pathway which is used.

Our conclusion that recombination between double-stranded DNA molecules in plants like in mammalian cells $(17-25)$ occurs predominantly by the SSA pathway is consistent with the studies of Puchta and Hohn (44) published during the preparation of this article. They used an approach which is very different to ours. Instead of measuring restoration of a kanamycin resistant phenotype and analyzing recombination products after integration into the genome they used a transient GUS assay to demonstrate in an elegant way that extrachromosomal recombination in plants is best explained by the SSA model. Contrary to our results they did not detect any recombination events according to the DSBR model. However, if the number of DSBR type recombinations we detected is related to the GUS values they obtained, it is within the range of the lowest values they observed. Therefore, the different experimental setup of their experiments may have prevented detection of recombination via the DSBR pathway. Nevertheless, together all these results confirm the observation in mammalian cells (22) that whether recombination products are studied before or after integration into the genome has no significant influence on the conclusions towards the recombination mechanisms.

The DSBR and SSA models as proposed for extrachromosomal recombination in mammalian cells are both based on the observation that double strand breaks at appropriate positions in the DNA molecules enhance recombination. As the introduction of double strand breaks in either one or both of the cotransformed DNA molecules could lead to a bias in the recombination process, we used in our cotransformation experiments only circular DNA molecules. Nevertheless, the analysis of products formed by recombination between two circular double-stranded DNA molecules clearly showed that such plasmids recombined predominantly by the SSA pathway, while this pathway requires two linear DNA molecules and as such double-strand breaks in both molecules. These results suggest that the generation of appropriate double strand breaks needed for the creation of complementary single-stranded DNA stretches is not a rate limiting step for intermolecular recombination in plant cells, just as it was suggested for mammalian cells (22). There the introduction of a double strand break in only one of the DNA duplexes still yielded exclusively recombination products predicted by the SSA model (22). Thus, we consider it likely that the introduction of a double-strand break in one or both DNA molecules will not cause a bias in the recombination process. That double strand breaks occur frequently in plants, as was also shown for mammalian cells $(45,46)$, was demonstrated by our observation that electroporation of tobacco protoplasts with circular and linear forms of pSDM2 generally gave a less than two-fold difference in transformation frequency (unpublished results). Although DNA is readily broken when introduced into the cell this happens probably in a random fashion. Thus, introduction of a double strand break at a defined position can still be beneficial for recombination.

Our finding that DNA is readily broken when introduced in a plant cell is remarkably different from that observed by Bilang et al. (47). Unless they introduced a double-strand break in both DNA molecules, they obtained either no or only a few recombinant clones when cotransforming tobacco protoplasts with two circular double-stranded DNA molecules. In an earlier paper (2) they already observed that the introduction of a double-strand break in one of the DNA duplexes did not stimulate recombination. This is contradictory to our results with cotransformation of pSDM1001 and pSDM1004, where we observed a fivefold increase in recombination frequency when we linearized the pSDM 1004 construct at the $3^{\prime}$ deletion (unpublished results). Introduction of a double-strand break in one of the DNA duplexes is beneficial to recombination in 
mammalian cells as well $(8,9,12-15,17,18,20,24,25)$. This discrepancy might be due to the fact that they used carrier DNA in their transformation protocol. The plant cell nucleases could be saturated by the carrier DNA, which could thus prevent the linearization of the plasmids.

As mentioned before, both the DSBR and SSA model suggest that single-stranded DNA plays an important role in recombination. This is also reflected by the action of recombination enzymes such as the RecA enzyme (48). After specific binding of single-stranded DNA this enzyme catalyses strand exchange in a homologous DNA duplex, a step vital for recombination. In our study we established the recombination ability of single-stranded DNA in plant cells by cotransforming single-stranded DNA with complementing double-stranded DNA molecules. The recombination frequencies (table 1) demonstrated that single-stranded DNA enters into recombination processes more efficiently than double-stranded DNA. For mammalian cells it was shown that single-stranded DNA can participate in recombination with a DNA duplex as efficiently as doublestranded DNA (14). However, in the yeast Saccharomyces cerevisiae (49) and the fungus Ascobolus immersus (50) singlestranded DNA interacted more efficiently with the chromosomal duplex compared to double-stranded DNA. Next to the higher recombination frequency we established that single-stranded DNA recombines differently from double-stranded DNA. Singlestranded DNA proved to recombine with equal frequencies via the SSA pathway and the DSBR pathway. As to the latter pathway we mainly observed single reciprocal recombination events and only limited gene conversion or double reciprocal recombination events. This can at least in part be explained by the location of the homologous regions. Most of the homologous sequences ( 600 bp) are located in between the mutations and only 150 bp is located upstream of the $5^{\prime}$ deletion. For gene conversion and a double reciprocal recombination both homologous sequences need to participate in recombination while for a single reciprocal recombination only the large stretch of homology is necessary.

Since the recombination of single-stranded DNA occurs differently from that of double-stranded DNA, we suppose that recombination takes place before single-stranded DNA is completely converted into double-stranded DNA. We (26) and others (27) have shown that tobacco protoplasts convert singlestranded DNA into double-stranded DNA within 48 hours after transformation. On the other hand, for mammalian cells (14) no conversion could be detected within that time and in yeast no conversion was detected within 18 hours (49). Although the results on conversion of single-stranded DNA into doublestranded DNA suggest that this might take at least 18 hours and the results of Folger et al. (10) suggest that recombination occurs within one hour after introduction of the DNA, it is possible that the introduced single-stranded DNA has become partially doublestranded before it enters into a recombination process. Further experiments are therefore needed to establish in more detail how single-stranded DNA recombines with double-stranded DNA.

An important question in studies on extrachromosomal recombination is whether the findings can be valuable for the design of gene targeting experiments. As shown previously $(5,51,52)$ gene targeting in plants is two to four orders of magnitude less frequent than extrachromosomal recombination. Establishing conditions for efficient gene targeting is seriously hampered by these low targeting frequencies. It would therefore be helpful if knowledge on extrachromosomal recombination could be used. It has been shown, for instance, that factors such as the introduction of double-strand breaks or the increase in the amount of homology stimulated recombination in both extrachromosomal recombination and gene targeting. On the other hand, for mammalian cells it has been demonstrated that the principal pathway for gene targeting is conservative (53) which suggest that the large difference in efficiency may represent the involvement of different mechanisms. In this report we demonstrated that extrachromosomal recombination between DNA duplexes occurred mainly via the SSA pathway. Extrapolation of this mechanism to recombination with a chromosomal gene would require a double-strand break in the chromosome. For yeast it was described that double-strand breaks can indeed occur in the chromosome and stimulate recombination $(54,55)$. In the fruitfly Drosophila melanogaster and the nematode Caenorhabditis elegans double-strand breaks occurred after excision of the P-element or the Tc-1 transposon, respectively $(56,57)$. These double-strand breaks were repaired by copying homologous sequences present in the genome or in extrachromosomal DNA. Nevertheless, at this moment it is unclear with what frequency double-strand DNA breaks occur in vivo in plant cells. Therefore, further research has to reveal whether extrachromosomal recombination and gene targeting in plant cells indeed use similar recombination pathways.

\section{ACKNOWLEDGEMENTS}

We wish to thank Jacob Blokker for constructing the pSDM8004 and pSDM9004 vectors. In addition we thank Nick Garner and Ben Cornelissen for critical reading of the manuscript and Peter Sijmons for valuable suggestions considering design of the figures. This work was supported by the Netherlands Foundation for Biological Research (BION) with financial support from the Netherlands Organization for the Advancement of Scientific Research (NWO).

\section{REFERENCES}

1. Wirtz,U., Schell,J. and Czemilofsky.A.P. (1987) DNA, 6, 245-253.

2. Baur,M., Potrykus,I. and Paszkowski,J. (1990) Mol. Cell. Biol., 10, $492-500$.

3. Puchta,H. and Hohn,B. (1991) Nucleic Acids Res., 19, 2693-2700.

4. Lyznik,L.A., McGee,J.D., Tung,P-Y., Bennetzen,J.L. and Hodges, T.K. (1991) Mol. Gen. Genet., 230, 209-218.

5. Offringa,R., De Groo,,M.J.A., Haagsman,H.J., Does,M.P., Van den Elzen,P.J.M. and Hooykaas,P.J.J. (1990) EMBO J., 9, 3077-3084.

6. Szostak,J.W., Orr-Weaver,T.L., Rothstein,R.J. and Stahl,F.W. (1983) Cell, $33,25-35$.

7. Ayares,D., Chekuri,L., Song,K-Y. and Kuchertapati,R. (1986) Proc. Nasl. Acad. Sci. USA., 83, 5199-5203.

8. Brenner,D.A., Smigocki,A.C. and Camerini-Otero,R.D. (1985) Mol. Cell. Biol., 5, 684-691.

9. Brenner,D.A., Smigocki,A.C. and Camerini-Otero,R.D. (1986) Proc. Natl. Acad. Sci. USA., 83, $1762-1766$.

10. Folger,K.R., Thomas,K. and Capecchi,M.R. (1985) Mol. Cell. Biol., 5 , $59-69$.

11. Jasin,M., de Villiers,J., Weber,F. and Schaffner,W. (1985) Cell, 43, 695-703.

12. Kucherlapati,R.S., Eves,E.M., Song,K-Y., Morse,B.S. and Smithies,O. (1984) Proc. Natl. Acad. Sci. USA, 81, 3153-3157.

13. Kucherlapati,R.S., Spencer,J. and Moore,P.D. (1985) Mol. Cell. Biol., 5, $714-720$.

14. Rauth,S., Song,K-Y., Ayares,D., Wallace,L., Moore,P.D. and Kucherlapati,R. (1986) Proc. Natl. Acad. Sci. USA, 83, 5587-5591.

15. Song,K-Y., Chekuri,L., Rauth,S., Ehrlich,S. and Kucherlapati,R. (1985) Mol. Cell. Biol., 5, 3331-3336.

16. Waldman,A.S. and Liskay,R.M. (1987) Proc. Natl. Acad. Sci. USA, 84, 5340-5344. 
17. Anderson,R.A. and Eliason,S.L. (1986) Mol. Cell. Biol., 6, 3246-3252.

18. Brouillette,S. and Chartrand,P. (1987) Mol. Cell. Biol., 7, 2248-2255.

19. Chakrabarti,S and Seidman, M.M. (1986) Mol. Cell. Biol, , 6, 2520-2536.

20. Lin,F-L., Sperte,K. and Stemberg,N. (1984) Mol. Cell. Biol., 4, 1020-1034.

21. Lin,F-L., Sperle,K.M. and Sternberg,N.L. (1987) Mol. Cell. Biol., 7, $129-140$.

22. Lin,F-L., Sperte,K. and Stemberg,N. (1990) Mol. Cell. Bid., 10, 103-112.

23. Lin,F-L., Sperte,K. and Stemberg,N. (1990) Mol. Cell. Biol., 10, 113-119.

24. Seidman,M.M. (1987) Mol. Cell. Biol., 7, 3561-3565.

25. Wake,C.T., Vernaleone,F. and Wilson,J.H. (1985) Mol. Cell. Biol., 5, 2080-2089.

26. Rodenburg,K., De Groot,M.J.A., Schilperoort,R.A. and Hooykaas,P.J.J. (1989) Plant Mol. Biol, 13, 711-719.

27. Fumer, I.J., Higgins, E.S. and Burrington, A.W. (1989) Mol. Gen. Genet., 220, 65-68.

28. Halfter,U. (1990) Dissertation, der Freien Universität Berlin.

29. Sambrook,J., Fritsch,E.F. and Maniatis, T. (1989) Molecular Cloning: A Laboratory Manual. Cold Spring Harbor University Press, Cold Spring Harbor.

30. Nagy,J.I. and Maliga,P. (1976) Z Pflanzenphysiol., 78, 453-455.

31. Shillito,R.D., Saul,M.W., Paszkowski,J., Muller,M. and Potrykus,I. (1985) Biotechnology, 3, 1099-1102.

32. Saul,M.W., Shillito,R.D. and Negrutiu,I. (1988) Plant Mol. Biol. Manual, $1-16$.

33. Murashige,T. and Skoog,F. (1962) Physiol. Plant, 15, 473-497.

34. Lassner,M.W., Peterson,P. and Yoder,J.I. (1989) Plant Mol. Biol. Rep., $7,116-128$.

35. Schocher,R.J., Shillito,R.D., Saul,M.W., Paszkowski,J. and Potrykus,I. (1986) Biotechnology, 4, $1093-1096$.

36. Kim,H-S. and Smithies,O. (1988) Nucleic Acids Res., 16, 8887-8903.

37. Zijlstra,M., Li,E., Sajjadi,F., Subramani,S. and Jaenisch,R. (1989) Narure, 342, 435-438.

38. Capecchi,M. (1989) Science, 244, 1288-1292.

39. Horton,R.M., Hunt,H.D., Ho,S.N., Pullen,J.K. and Peace,L.R. (1989) Gene, 77, 61-68.

40. Yotov,A.A. and Shabarova,Z.A. (1990) Nucleic Acids Res., 18, 3983-3986.

41. Klug,J., Wolf,M. and Beato,M. (1991) Nucleic Acids Res., 19, 2793.

42. Czernilofsky,A.P., Hain,R., Herrera-Estrella,L., Lörz,H., Goyvaerts, E., Baker,B. and Schell,J. (1986) DNA, 5, 101-113.

43. Riggs,C.D. and Bates,G.W. (1986) Proc. Narl. Acad. Sci. USA, 83, $5602-5606$.

44. Puchta,H. and Hohn, B. (1991) Mot Gen Genet, 230, 1-7.

45. Folger,K.R., Wong,E.A., Wahl,G. and Capecchi,M.R. (1982) Mol. Cell. Biol., 2, 1372-1387.

46. Wake,C.T., Gudewicz,T., Ponter, T, White,A. and Wilson, J.H. (1984) Moll. Cell. Biol., 4, 387-398.

47. Bilang,R., Peterhans, A., Bogucki,A. and Paszkowski,J. (1992) Moll. Cell. Biol., 12, 329-336.

48. Cox,M.M., Lehman,I.R. (1987) Annu. Rev. Biochem., 56, 229-262.

49. Simon,J.R. and Moore,P.D. (1987) Mol. Cell. Biol., 7, 2329-2334.

50. Goyon,C. and Faugeron,G. (1989) Mot. Cell. Biot,, 9, 2818-2827.

51. Paszkowski,J., Baur,M., Bogucki,A. and Potrykus,I. (1988) EMBO J., 7, $4021-4026$.

52. Halfter,U., Morris,P-C. and Willmizzer,L. (1992) Mol. Gen. Genet., 231, $186-193$.

53. Pennington,S.L. and Wilson,J.H. (1991) Proc. Natl. Acad. Sci. USA., 88, 9498-9502.

54. Nicolas,A., Treco,D., Schultes,N.P. and Szostak,J.W. (1989) Narure, 338, $35-39$.

55. Sun,H., Treco,D., Schultes,N.P. and Szostak,J.W. (1989) Nature, 338, $87-90$.

56. Gloor,G.B., Nassif,N.A., Johnson-Schlitz,D.M., Preston,C.R. and Engels,W.R. (1991) Science, 253, 1110-1117.

57. Plasterk,R.H.A. and Groenen,J.T.M. (1992) EMBO J., 11, 287-290. 